\title{
Encounters between Antarctic limpets, Nacella concinna, and predatory sea stars, Lysasterias sp., in laboratory and field experiments
}

\author{
Marta Markowska • Anna Kidawa
}

Received: 14 October 2004 / Accepted: 28 January 2007 / Published online: 15 February 2007

(C) Springer-Verlag 2007

\begin{abstract}
Antarctic limpets, Nacella concinna, from the Admiralty Bay (King George Island, South Shetlands) for at least part of the year (austral winter) coexist with predatory sea stars Lysasterias sp. Our laboratory and field experiments established that the presence of Lysasterias sp. or its odour had considerable influence upon their behaviour. Limpets' responses, consisting of shell mushrooming, shell rotation and flight, were distinctly different from their reaction to other stimuli, such as food and conspecific odours, or mechanical stimulation. Moreover, a significant impact of sea star presence on limpets' activity was observed, with limpets fleeing to a distance of $60 \mathrm{~cm}$ from the predator. Such reactions allow limpets to lower the incidence of sea star predation, but at the cost of presumptive disrupting of foraging and an additional energy expended for locomotion. A visible difference was noted between two limpet populations, with the rockpool limpets responding only after physical contact with being touched by a sea star, and the subtidal ones responding at a distance of up to $20 \mathrm{~cm}$.
\end{abstract}

\section{Introduction}

Many marine invertebrates exhibit escape behaviours in response to the presence of gastropod and sea star

Communicated by O. Kinne.

M. Markowska $(\bowtie) \cdot$ A. Kidawa

Department of Antarctic Biology,

Polish Academy of Sciences,

ul. Ustrzycka 10, 02-141 Warsaw, Poland

e-mail:markowskam@yahoo.com predators, limiting the number of dangerous encounters and reducing the risk of consumption (Phillips 1978; Peckarsky 1980; McClintock 1985; Marko and Palmer 1991; Scheibling and Hamm 1991; McKillup and McKillup 1994). Such behaviour may be mediated by both physical and chemical stimuli (Phillips 1978; Vadas et al. 1986; Marko and Palmer 1991; Mahon et al. 2002), and may have considerable effect on spatial and temporal activity patterns in prey species (Leber 1985; Vadas et al. 1986; Marko and Palmer 1991; Scheibling and Hamm 1991; Sparrevik and Leonardsson 1995; Rochette et al. 1997; Rochette et al. 2001).

Antarctic and sub-Antarctic limpets (Patellidae) are known to display escape responses to predatory sea stars (Walker 1972; Simpson 1976; Blankley and Branch 1984; McClintock 1985; Mahon et al. 2002). Behaviours such as shell mushrooming, shell rotation and flight have been observed in response both to physical contact with a predatory sea star and exposure to crude hydrophilic extracts made from sea star body tissues (McClintock 1985; Mahon et al. 2002). Observations on Chilean intertidal limpets showed that different species have developed contrasting strategies (active escape versus passive defense) when encountering predatory sea stars (Espoz and Castilla 2000). Branch (1979) noticed two types of reaction of limpets Patella oculus and P. granatina towards predatory sea stars Marthasterias glacialis (escape in small individuals and aggressive behaviour in large ones).

The Antarctic limpet Nacella concinna (Strebel, 1908) is a characteristic and ecologically important component of the Antarctic benthos and occurs from the intertidal zone down to depths of $110 \mathrm{~m}$ (Picken 1980) on rocky bottoms (Berry and Rudge 1973) along 
the Antarctic Peninsula and adjacent islands (Picken 1980). It is herbivorous and feeds on benthic microalgae (Shabica 1976; Davenport 1997). At the onset of the austral fall individuals abandon intertidal and subtidal zones and migrate deeper presumably to escape low air temperatures and ice formation in the intertidal zone (Walker 1972). Subtidal N. concinna often cooccur with the predatory sea stars such as Neosmilaster georgianus, Odontaster validus and/or Lysasterias sp. (Mahon et al. 2002; M. Markowska, personal observations). $N$. concinna has previously been shown to display escape behaviour to the sea star Ne. georgianus, but no escape response to the sea star $O$. validus (Mahon et al. 2002).

The purpose of present study was to investigate the escape behaviours of $N$. concinna in response to the sympatric predatory sea star Lysasterias sp. Moreover, the present study explores the impact of a predator on the spatial dislocation of its limpet prey using both laboratory and fields manipulations. Finally, we compared escape responses of intertidal and subtidal populations of $N$. concinna to determine whether populations exposed to different levels of sea star predator risk respond differently.

\section{Materials and methods}

Limpets were gathered from Admiralty Bay (King George Island, South Shetlands) by hand from rockpools during the low tide and by divers from the subtidal area (5-8 $\mathrm{m}$ of depth). Individuals were maintained in well-aerated 101 non-flow tanks for 1 day prior to experiments. Conditions in these tanks (and all subsequent aquarium experiments) were maintained at $0-0.5^{\circ} \mathrm{C}$ and $34.2-34.5$ PSU. Limpets collected from rockpools were significantly smaller than subtidal individuals ( $t$ test, $P<0.005)$, ranging from 19.8 to $43.3 \mathrm{~mm}$ shell length $($ mean $=21.2$, $\mathrm{SE}=0.32 \mathrm{~mm}, n=222$ ), in comparison to $23.7-47.0 \mathrm{~mm}$ (mean $=37.4, \mathrm{SE}=0.49, n=191)$ for the subtidal ones.

Sea stars Lysasterias sp. with a radius of $4.5-6.2 \mathrm{~cm}$ (measured from the oral opening to the tip of the longest arm) were caught in baited traps (set at depth of $15 \mathrm{~m}$ ) from the Admiralty Bay (King George Island, South Shetlands). Animals were maintained in wellaerated tanks (ca. 301 each). To minimize differences in their feeding status they were fed Notothenia sp. muscle meat for a week and then starved for 2 weeks prior to experiments.

Behavioural observations were carried out on limpets placed individually in small aquaria (ca. 1.51). Individuals were left there for $15 \mathrm{~min}$, allowing them to reaffix themselves. Limpets were then exposed to the following stimuli: sea star odour, conspecifics odour, microalgal extract, pure sea water, mechanical stimuli or the presence of a live sea star. Sea star odour was obtained from the aquarium that had held two starved Lysasterias sp. for $24 \mathrm{~h}$. Limpet odour was obtained from the aquarium that held a group of 10 adult limpets for $24 \mathrm{~h}$. Microalgal extract was obtained by grinding sympatric microalgae (mainly diatoms) encrusting rocks on which limpets were found grazing. Mechanical stimulation was produced by gently touching the shells of limpets with a glass rod. Sea star stimulation was produced by placing a live starved specimen of Lysasterias sp. close to a limpet with one arm tip in contact with its shell. In all experiments, limpet behaviours were monitored for $5 \mathrm{~min}$ and their behavioural responses were observed (clamping to substrate, pallial tentacles waving, cephalic tentacles waving, shell mushrooming, shell rotation and flight). Each experiment was replicated 40 times (20 times for rockpool limpets and 20 for subtidal ones). Individual limpets were never used for the same test stimulus more than once. As there was no statistically significant differences between the responses of subtidal and rockpool limpets to any of these stimuluses applied in the laboratory experiments (mean reaction times $t$ Student's test, $P<0.05$; number of limpets displaying each behavioural reaction $\chi^{2}$ test, $P<0.005$ ), both sets of results were pooled together.

Additional behavioural observations of limpets in their natural environment were made by divers by placing a starved specimen of Lysasterias sp. close to individual subtidal limpets, with one arm tip touching the shell. Limpet behaviours (see above) were monitored for $5 \mathrm{~min}$. In control experiments limpets-freely grazing with no danger from predatory sea stars-were observed for the same amount of time. Each experiment was replicated 20 times. Again, no animal was used more than once.

The impact of sea star presence on limpet spatial dislocation in the laboratory was examined in $40 \times 60 \mathrm{~cm}$ aquaria, with a group of four limpets placed in the central part of each aquarium. The animals were left there for $5 \mathrm{~min}$, allowing them to reattach themselves. As the aquarium bottom was not covered with microalgae, the animals had no incentive to move or graze, and sat immobile in the place they were put. After that time a sea star was placed in the aquarium, about $30 \mathrm{~cm}$ from the limpets. Almost instantaneously it began to move towards the gastropods, reaching them in ca. $1.5 \mathrm{~min}$. The sea star was removed from the aquarium after $5 \mathrm{~min}$, and limpets behaviour was observed for further $5 \mathrm{~min}$. Animal positions were noted with the help of a 
grid on the bottom of the aquarium. Each experiment was replicated 20 times (10 times for the rockpool limpets, and 10 the subtidal ones) using different individuals each time.

The impact of sea star presence on limpet spatial dislocation in the natural environment was done in both the subtidal area and in rockpools. Observations were made after placing a starved specimen of Lysasterias $\mathrm{sp}$. a few $\mathrm{cm}$ from naturally occurring groups of feeding limpets (subtidal zone), or resting limpets (rockpools during low tide). The area of rockpools in which experiments were conducted varied from 400 to $3,500 \mathrm{~cm}^{2}$, with the number of limpets ranging from 6 to 41 . No experiments were done when the water temperature in the rockpool exceeded $2.5^{\circ} \mathrm{C}$, as preliminary observations revealed stress symptoms in sea stars under these conditions (their tube feet were extended only partially, they moved sluggish, and attempted to exit the rockpool). In the subtidal zone at 5-8 $\mathrm{m}$ depth limpets were distributed unevenly, in clusters from 3 to 10 individuals, at a mean density of $10 \mathrm{ind} / \mathrm{m}^{2}$. Maps of locations were made before the experiments and limpets' positions were marked on them. Sea stars were removed after $5 \mathrm{~min}$, and limpets behaviour was monitored for the further $5 \mathrm{~min}$. Each experiment was replicated 10 times each for subtidal and intertidal limpets.

\section{Results}

Behavioural observations

Limpets showed virtually no behavioural reaction to controls consisting of pure sea water, and sat immobile on the aquarium bottom with pallial tentacles extended outside their shells.

Mechanical stimuli, microalgal extract or conspecifics odour elicited responses from $60 \%$ of limpets (Fig. 1). Gastropods touched with a glass rod reacted by instantaneously hiding pallial tentacles and clamping down on the aquarium bottom (Fig. 2). A return to the initial position was observed after $15.5 \pm 1.7 \mathrm{~s}$ (mean $\pm \mathrm{SE})$.

Limpet reaction to microalgal extract consisted of waving the pallial tentacles on the anterior part of the body, shell rising and probing with the cephalic tentacles (Fig. 3). No individual was displayed more than two of these types of behaviour simultaneously. Similar components of behaviour were noticed by divers observing limpets grazing on microalgae in their natural environment. Time from stimulus release to animal reaction was $30 \pm 5.07 \mathrm{~s}($ mean $\pm \mathrm{SE})$.

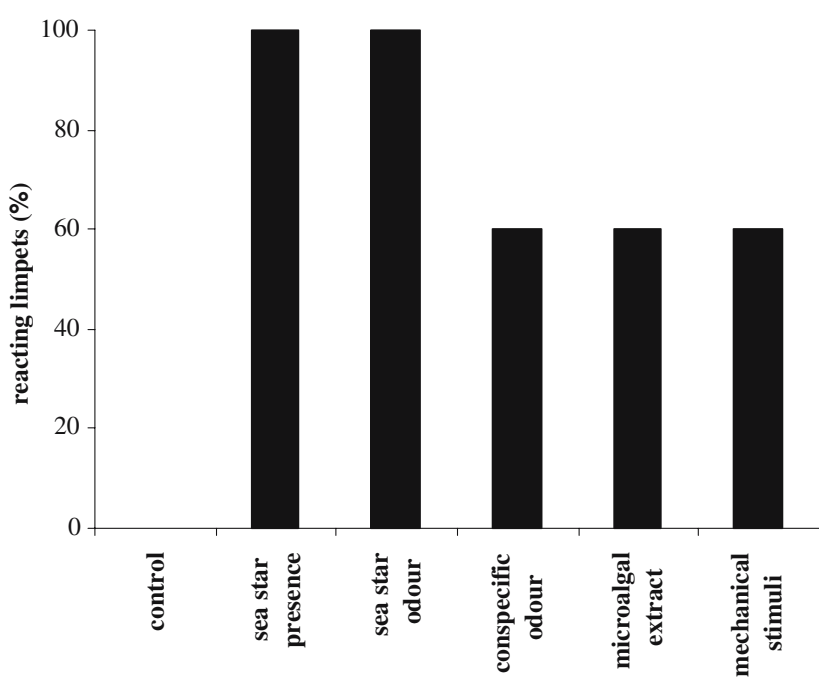

Fig. 1 Percentage of limpets $N$. concinna reacting to different types of stimuli (control pure seawater)

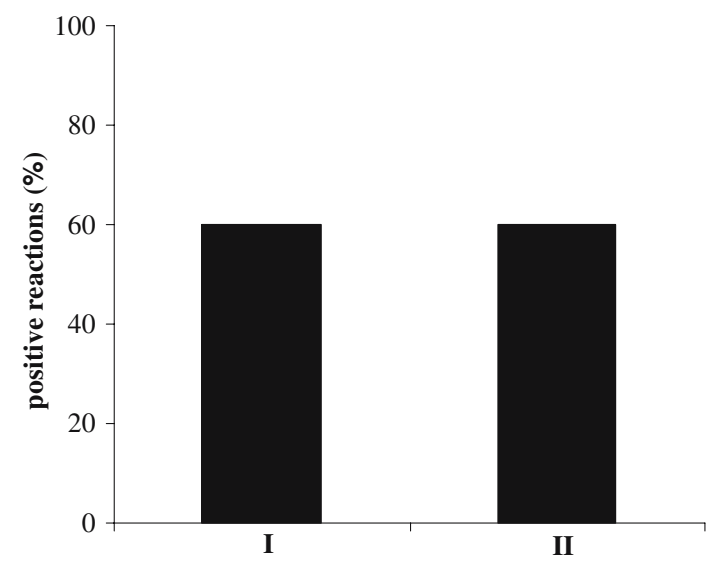

Fig. 2 Behavioural responses of limpets $N$. concinna to mechanical stimuli. Positive behavioural responses are divided into types: $I$ hiding pallial tentacles, $I I$ clamping down on aquarium bottom

The response of limpets to conspecifics odour consisted of waving pallial and/or cephalic tentacles (Fig. 4). Time from stimulus release to animal reaction was $11.7 \pm 1.7 \mathrm{~s}$ (mean $\pm \mathrm{SE})$.

All limpets reacted to Lysasterias sp. "odour" (Fig. 1), displaying such types of behaviour as pallial tentacles waving, cephalic tentacles extension, shell mushrooming, shell rotation, and flight (Fig. 5). From stimulus release to animal reaction took $16.05 \pm 4.58 \mathrm{~s}$ (mean $\pm \mathrm{SE}$ ). No individuals displayed all types of behaviour simultaneously, but $80 \%$ of them displayed more than one type of behaviour. Only $20 \%$ of limpets reacted with flight, but as many as $60 \%$ of them displayed shell raising and/or rotation.

All limpets reacted to the presence of a live Lysasterias $\mathrm{sp}$. (Fig. 1), displaying such behaviour types as shell mushrooming, shell rotation and flight (Fig. 6). 


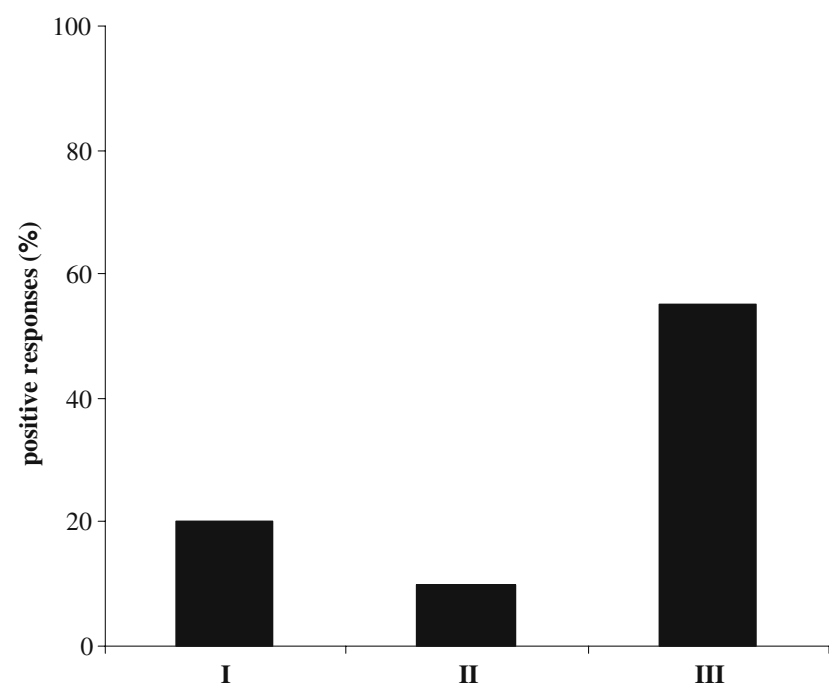

Fig. 3 Behavioural responses of limpets $N$. concinna to microalgal extract. Positive behavioural responses are divided into types: $I$ pallial tentacles waving, $I I$ shell rising, $I I I$ cephalic tentacles probing

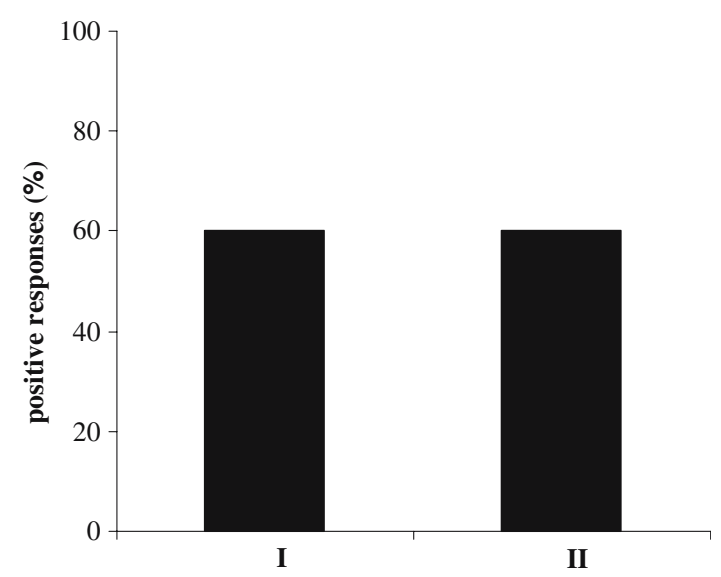

Fig. 4 Behavioural responses of limpets $N$. concinna to conspecifics' odour. Positive behavioural responses are divided into types: I pallial tentacles waving, II cephalic tentacles waving

All limpets touched by a live sea star reacted with flight, and-additionally, $90 \%$ of them-with mushrooming. Mean time between stimulus and animal reaction was $15.5 \pm 3.02 \mathrm{~s}$ (mean $\pm \mathrm{SE}$ ).

Observations and manipulations done by divers in subtidal zone showed that all limpets touched by Lysasterias sp. responded with instant mushrooming and flight. The height attained by these limpets during mushrooming was twice as great as in the laboratory experiments and was two times higher than limpet shell height.

\section{Position experiments}

In the laboratory experiments all limpets from the rockpools or the subtidal sites fled from the presence of

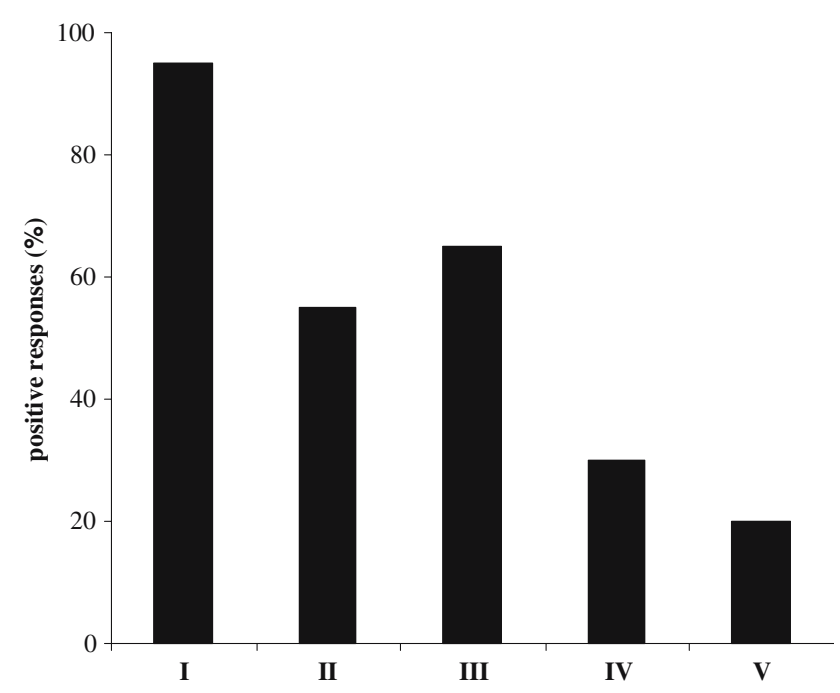

Fig. 5 Behavioural responses of limpets $N$. concinna to sea star odour. Positive behavioural responses are divided into types: $I$ pallial tentacles waving, $I I$ cephalic tentacles extension, III shell mushrooming, $I V$ shell rotation, $V$ flight

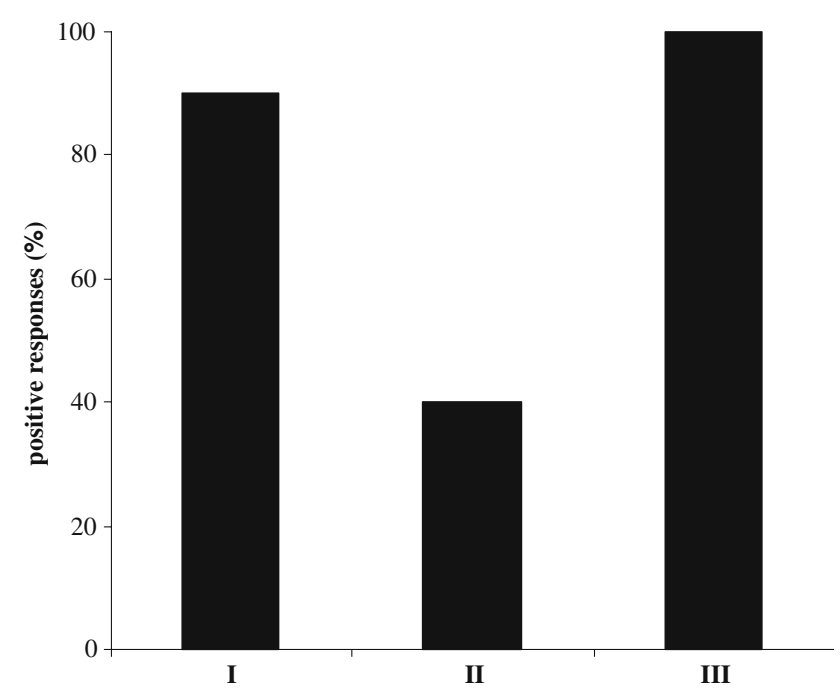

Fig. 6 Behavioural responses of limpets $N$. concinna to live sea star presence. Positive behavioural responses are divided into types: $I$ shell mushrooming, $I I$ shell rotation, $I I I$ flight

Lysasterias $\mathrm{sp}$. Individuals from rockpools reacted only upon being contacted by a sea star, whereas limpets collected from the subtidal site displayed flight when a moving sea star came within a distance of $2-4 \mathrm{~cm}$. As limpets were gathered in a tight group in the aquarium centre, all of them reacted at approximately the same time (there was no statistically significant difference between reaction time of limpets within the group, Student's $t$ test, $P<0.05$ ).

There was a significant statistical difference between distances covered by fleeing rockpool and subtidal limpets in laboratory during the 10-min experiments 
(Mann-Whitney $U$ test, $P<0.05$ ), with subtidal limpets escaping much further (by $48 \%$ ) than rockpool ones (Table 1). Statistically significant difference was observed between flight speeds of rockpool and subtidal limpets with the latter moving faster (MannWhitney $U$ test, $P<0.05$ ).

Most of limpets' locomotory activity occurred during the first $5 \mathrm{~min}$ of experiment, i.e. before the removal of the sea star. During this time period rockpool limpets travelled a mean distance of $10.8 \mathrm{~cm}$ $(\mathrm{SE}=0.9 \mathrm{~cm})$ and the subtidal ones $17.5 \mathrm{~cm}(\mathrm{SE}=$ $0.9 \mathrm{~cm})$. This difference was statistically significant (Mann-Whitney $U$ test, $P<0.05$ ). After sea star removal, all subtidal limpets and $82.5 \%$ of the rockpool ones continued their flight, although distances covered by them $(10.4 \pm 0.9 \mathrm{~cm}$ for subtidal animals and $8.0 \pm 1.8 \mathrm{~cm}$ for the rockpool ones) were significantly shorter than during the first period of observation (Mann-Whitney $U$ test, $P<0.05$ ).

In field experiments, the percentage of rockpool limpets reacting to the presence of Lysasterias sp. ranged from 20 to $89 \%$. Only individuals contacted by a moving sea star displayed a flight response. Almost $19 \%$ of them crawled out of water (one of the individuals travelled several centimetres to the next rockpool). Mean distance covered by escaping animals was $11.2 \mathrm{~cm}$ (Table 1), which was significantly less than in the instance of laboratory experiments (Mann-Whitney $U$ test, $P<0.05)$. In field experiments it was not possible to divide distance covered by limpets in two 5 min periods, because the gastropods did not begin to move at the same time. As they were initially dispersed over quite a large area, there was a significant time gap between different limpets being touched by the slowly moving sea star. Nethertheless, it was observed that $70 \%$ of escaping limpets continued their flight after the removal of a sea star from the rockpool.

Table 1 Flight speed and distance covered by limpets Nacella concinna fleeing from a starved specimen of the sea star Lysasterias $\mathrm{sp}$. in laboratory and field experiments

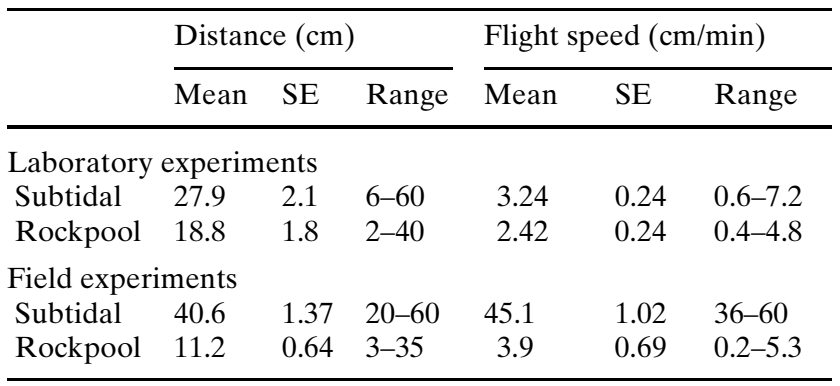

Data from the laboratory experiments and the field rockpool experiments were calculated for $10 \mathrm{~min}$ periods of observation; data for field subtidal experiments for the duration of limpet flight $(\max .2 \mathrm{~min})$
In the subtidal experiments, all limpets reacted to the presence of Lysasterias sp. Even individuals as far as $20 \mathrm{~cm}$ from the sea star began escaping. Mean distance covered by fleeing animals was $40.6 \mathrm{~cm}$ (Table 1), and was significantly greater than in all other experiments (Mann-Whitney $U$ test, $P<0.05$ ). Limpets' locomotion ceased after they reached a distance of $40-60 \mathrm{~cm}$ from the predator. Due to high speeds attained by them, the whole burst of locomotory activity was exceptionally short, and did not exceed $2 \mathrm{~min}$.

\section{Discussion}

Our experiments indicate that the common Antarctic limpet $N$. concinna discriminates between different chemical and/or physical signals. Alarm signals (sea star contact or odour) elicited the strongest behavioural responses, as all individuals exposed to sea stars reacted in comparison to only $60 \%$ of limpets exposed to other stimuli. The behavioural responses to Lysasterias $\mathrm{sp}$., i.e., shell mushrooming, shell rotation and flight, were identical to those described for $N$. concinna placed in contact with the predatory sea star Ne. georgianus (Mahon et al. 2002). McClintock (1985) noticed similar behaviour in the sub-Antarctic limpet Nacella edgari placed a short distance from the predatory sea star Anasterias perrieri. Another sub-Antarctic limpet, $N$. macqueriesis, was observed displaying escape behaviour to the sea stars Anasterias directa and A. perrieri (Simpson 1976). Thus, it can be assumed that escape responses of Antarctic and sub-Antarctic limpets to sea star predators are probably a common occurrence (Mahon et al. 2002).

Mahon et al. (2002) noted, that although N. concinna reacted vigorously to the sea star Ne. georgianus, it did not display escape responses to Odontaster vali$d u s$, an unselective omnivorous sea star that can act as an active predator, a scavenger or a herbivore. Mahon et al. (2002) suggested that Ne. georgianus-a highly mobile sea star with long, narrow arms-may be more adept at feeding on limpets than $O$. validus with its short, web-like arms. Our laboratory observations showed that long arms of Lysasterias sp. were flexible and capable of complicated manipulations. Additionally, Lysasterias sp. can move at rates that are approximately six times greater than those observed in $O$. validus (A. Kidawa, personal observations). Thus, we can assume that $N$. concinna can assess the relative risks posed by different species of sea stars, and respond to them by fleeing from dangerous species and ignoring others. During our underwater manipulations it was observed that one of the limpets escaping from 
Lysasterias sp. fled into the arms of a nearby $O$. validus, moving over the sea star without any change of direction (M. Markowska, personal observation). In contrast, when the second sea star encountered was another Lysasterias sp., limpets executed a rapid change of direction, and only after this carried on the escape process (M. Markowska, personal observation). A similar phenomenon was also observed by Espoz and Castilla (2000) for the Chilean intertidal limpet Lottia orbignyi, which vigorously reacted to the sea star Heliaster helianthus, a known limpet consumer, and displayed almost no reaction to Patiria chilensis and Stichaster striatus, which have never been reported to prey on limpets (Espoz and Castilla 2000).

The signal responsible for $N$. concinna detecting the presence of sea stars is probably chemical in nature. Our observations showed that limpets exposed to sea star odour displayed changes in behaviour similar (although weaker) to those provoked by contact with or the presence of a nearby sea star. Similar results of chemically mediated escape responses to predators were reported earlier for limpets (McClintock 1985; Espoz and Castilla 2000; Mahon et al. 2002) and other marine invertebrates (Marko and Palmer 1991; Vadas et al. 1994; Morton et al. 1995; Moore and Howarth 1996; Rochette and Himmelman 1996). In contrast to previous limpet studies in which sea star homogenates were utilized (Espoz and Castilla 2000; Mahon et al. 2002), we used sea water from the aquarium in which live Lysasterias sp. were kept as the danger signal informing limpets of a predator presence. In their natural environment limpets will certainly be more often exposed to the effluents from a live sea star than to a sea star homogenate.

Our underwater observations showed that sea star presence had a visible and clear effect on limpet position, with limpets fleeing a distance of up to $60 \mathrm{~cm}$. In laboratory experiments no instances of limpets climbing aquarium walls were observed. Even when a fleeing limpet reached aquarium wall, it changed direction and travelled parallel to it.

Our data on dispersal distances of escaping rockpool limpets in the laboratory and field experiments were similar to those reported for the Chilean intertidal limpets L. orbignyi and Scurria viridula (Espoz and Castilla 2000) and much lower than the values measured by us for subtidal N. concinna. Speed of Antarctic limpets fleeing from sea stars was previously measured only in the laboratory and ranged from $3.9 \mathrm{~cm} / \mathrm{min}$ for $N$. concinna (Mahon et al. 2002) to $12 \mathrm{~cm} / \mathrm{min}$ for N. edgari (McClintock 1985). These values and our data for rockpool limpets in laboratory and field experiments, and subtidal limpets in laboratory experiments are visibly lower than the speed of $45.1 \mathrm{~cm} / \mathrm{min}$ attained by subtidal limpets in our underwater experiments. Under these conditions, limpets displayed short, very intensive bursts of locomotion rather than rather long, prolonged periods of slower locomotion as observed in laboratory experiments. Significant differences between escape behaviours of subtidal limpets in laboratory and field experiments reveal the importance of underwater observations and manipulations, and underscore the difficulties connected with using laboratory observations to explain ecological processes in the animals' natural environment.

In our behavioural experiments no differences were observed between limpets from rockpool and subtidal populations. On the other hand behavioural experiments in which both limpets and Lysasterias sp. could move about freely showed distinct differences in the reaction of these populations, with the rockpool limpets reacting only upon being touched by a sea star (both laboratory and field experiments), and subtidal limpets responding to it from the distance of $2-4 \mathrm{~cm}$ (laboratory experiments) or $20 \mathrm{~cm}$ (underwater field experiments). Mahon et al. (2002) reported that no reaction of $N$. concinna was observed before physical contact with the predatory sea star Ne. georgianus. In contrast, the sub-Antarctic limpet $N$. edgari responded to the predatory sea star $A$. perrieri at a distance of about $6 \mathrm{~cm}$ (McClintock 1985). It can putatively be hypothetized that $N$. concinna can distinguish between different species of predatory sea stars, and the dissimilarity of the response is due to difference in perceived threat. This disparity might also have been caused by differences in the experimental methodology (freemoving sea stars versus those manipulated by hand). This explanation implies that the limpets can distinguish between un-stressed and stressed predators, and appropriately modify their reaction. Phillips (1978) noted that the sea urchin, Strongylocentrotus purpuratus, has the ability to distinguish between actively foraging and inactive individuals of the predatory sea star Pycnopodia helianthoides. In our field observations in rockpools we noticed that on sunny days when water temperature exceeded $8^{\circ} \mathrm{C}$, limpets showed virtually no reaction to Lysasterias sp. The sea stars placed in such conditions were behaving differently than in lower $\left(1.5-2.5^{\circ} \mathrm{C}\right)$ temperatures. Their tube feet were extended only partially, they moved sluggishly, and attempted to exit the rockpool.

Espoz and Castilla (2000) noted that two relatively primitive limpet species displayed strong escape reactions to the predatory sea star Heliaster helianthus, whereas two more derived limpet species did not exhibit such behaviours. In the present study, differences in 
limpet escape responses to the predator were observed between two populations of the same species. Subtidal limpets came from an environment where they co-exist with different species of sea stars and where the risk of being preyed upon was probably quite significant. Additionally, in subtidal environments the absence or reduction of tidal currents and wave action made chemoreception a more feasible means of detecting the position of predators then in the intertidal zone. In contrast, rockpool limpets were living in the intertidal zone, where the presence of sea stars was only incidental, and the chance of encountering a sea star was almost nonexistent. Moreover, continuous water mixing by waves and tidal currents would also have reduced the effectiveness of distance chemoreception. At the beginning of the Antarctic winter both intertidal and subtidal populations of $N$. concinna migrate deeper (Walker 1972), where the likelihood and danger of encountering a predatory sea star is likely quite high. Therefore, we assume that $N$. concinna can modify its strategy of dealing with the presence of predators, depending on the probability of such encounters, with subtidal limpets, which coexist with predatory sea stars for the entire year, using distance detection and an avoidance strategy, whereas the intertidal ones, which for the part of the year live in the environment devoid of such predators, escaping only when touched by a sea star.

Significant differences between two Antarctic limpet populations living in tidal and subtidal environments were also noticed by other authors. Nolan (1991) observed differences in size, shape and shell morphology between both populations, attributed by him to a combination of behavioural and stress-induced factors. Similar shape differences between both populations were also found by Beaumont and Wei (1991). Additionally, a study of allelic variation, based on the examination of five enzyme loci, revealed no discernible differences between tidal and subtidal population of Antarctic limpets at Signy Island which suggests environmentally induced, phenotypic changes as being responsible for the observed differences (Beaumont and Wei 1991). Such significant morphometric difference between both Antarctic limpet populations suggests that limpets from the tidal population return to their environment when winter is over. Only further underwater behavioural observations during Antarctic winter can solve the issue of plastic versus fixed limpet' behavioural response to predatory sea star presence.

Acknowledgments Data presented in this study were collected during the XXVIII Polish Antarctic Expedition at H. Arctowski Station (King George Island, South Shetlands). The work was financed by the State Committee for Scientific Research grant 3 P04F 02325 (years 2003-2006). We would like to thank two anonymous reviewers for constructive advice that has improved our paper.

\section{References}

Beaumont AR, Wei JHC (1991) Morphological and genetic variation in the Antarctic limpet Nacella concinna (Strebel, 1908). J Moll Stud 57:443-450

Berry RJ, Rudge PJ (1973) Natural selection in Antarctic limpet. Br Antarct Surv Bull 35:73-81

Blankley WO, Branch GM (1984) Co-operative prey capture and unusual brooding habits of Anasterias rupicola (Verrill) (Asteroidea) at sub-Antarctic Marion Island. Mar Ecol Prog Ser 20:171-176

Branch GM (1979) Aggression by limpets against invertebrate predators. Anim Behav 27:408-410

Davenport J (1997) Comparisons of the biology of the intertidal subantarctic limpets Nacella concinna and Kerguelenella lateralis. J Moll Stud 63:39-48

Espoz C, Castilla JC (2000) Escape responses of four Chilean intertidal limpets to seastars. Mar Biol 137:887-892

Leber KM (1985) The influence of predatory decapods, refuge, and mirohabitat selection on seagrass communities. Ecology 66(6):1951-1964

Mahon AR, Amsler CD, McClintock JB, Baker BJ (2002) Chemo-tactile predator avoidance responses of the common Antarctic limpet Nacella concinna. Polar Biol 25:469-473

Marko PB, Palmer R (1991) Responses of a rocky shore gastropod to the Effluents of predatory and non-predatory crabs: avoidance and attraction. Biol Bull 181:363-370

McClintock JB (1985) Avoidance and escape responses of the Sub-Antarctic limpet Nacella edgari (Powell) (Mollusca: Gastropoda) to the seastar Anasterias perrieri (Smith) (Echinodermata: Asteroidea). Polar Biol 4:95-98

McKillup SC, McKillup RV (1994) The decision to feed by a scavenger in relation to the risks of predation and starvation. Oecologia 97:41-48

Moore PG, Howarth J (1996) Foraging by marine scavengers: effects of relatedness, bait damage and hunger. J Sea Res 36:267-273

Morton B, Chan K, Britton JC (1995) Hunger overcomes fear in Nassarius festivus, a scavenging gastropod on Hong Kong shores. J Moll Stud 61:55-63

Nolan CP (1991) Size, shape and shell morphology in the Antarctic limpet Nacella concinna at Signy Island, South Orkney Islands. J Moll Stud 57:225-238

Peckarsky BL (1980) Predator-prey interaction between stoneflies and mayflies: behavioral observations. Ecology 61(4):932-943

Phillips DW (1978) Chemical mediation of invertebrate defensive behaviors and the ability to distinguish between foraging and inactive predators. Mar Biol 49:237-243

Picken GB (1980) The distribution, growth and reproduction of the Antarctic limpet Nacella (Patinigera) concinna (Strebel 1908). J Exp Mar Biol Ecol 42:71-85

Rochette R, Himmelman JH (1996) Does vulnerability influence trade-offs made by whelks between predation risk and feeding opportunities? Anim Behav 52:783-794

Rochette R, Dill LM, Himmelman JH (1997) A field test of threaty sensitivity in a marine gastropod. Anim Behav 54:1053-1062 
Rochette R, Tetreault F, Himmelman JH (2001) Aggregation of whelks, Buccinum undatum, near feeding predators: the role of reproductive requirements. Animal Behav 61:31-41

Scheibling RE, Hamm J (1991) Interaction between sea urchins (Strongylocentrotus droebachiensis) and their predators in field and laboratory experiments. Mar Biol 110:105-116

Shabica SV (1976) The natural history of the Antarctic limpets Patinigera polaris (Hombron and Jacquinot). Ph D Thesis, Oregon State University, Corvallis, p 294

Simpson RD (1976) Physical and biotic factors limiting the distribution and abundance of littoral mollusks on Macquerie Island (subantarctic). J Exp Mar Biol Ecol 21:11-49

Sparrevik E, Leonardsson K (1995) Effects of large Saduria entomon (Isopoda) on spatial distribution of their small S. ento- mon and Monoporeia affinis (Amphipoda) prey. Oecologia 101:177-184

Vadas RL, Burrows MT, Hughes RN (1994) Foraging strategies of dogwhelks, Nucella lapillus (L.): interacting effects of age, diet and chemical cues to the threat of predation. Oecologia 100:439-450

Vadas RL, Elner RW, Garwood PE, Babb IG (1986) Experimental evaluation of aggregation behavior in the sea urchin Strongylocentrotus droebachiensis. Mar Biol 90:433-448

Walker AJM (1972) Introduction to the ecology of the Antarctic limpets Patinigera polaris (Hombron and Jacquinot) at Signy Island, South Orkney Islands. Br Antarct Surv Bull 28:49-71 